\title{
A Comparison of Hydrological Models Under Climate Change on the Water Resources of Megech River Catchment, Abbay Basin, Ethiopia
}

\author{
Endalkachew Abebe ${ }^{1} \quad$ Asfaw Kebede ${ }^{2}$ \\ 1.Researcher and lecturer, Guna Tana Integrated Field Research and Development Center, Debre Tabor \\ University, Debre Tabor, Ethiopia \\ 2.Assocate Professor, School of Natural Resource and Environmental Engineering, Institute of Technology, \\ Haramaya University, Dire Dawa, Ethiopia
}

\begin{abstract}
This study was aimed to compare the uncertainty of two hydrological models in discharge modeling and their performance and catchment hydrological response to climate change in Megech river catchment. In this study, large scale regional climate model (REMO) output was downscaled statistically to metrological variables at a daily resolution using SDSM model version 5.11. The two hydrological models, HBV-Light and GR4J, were successfully calibrated (1991-1995) and validated (1998-2000) using current climatic inputs and observed river flows. The overall performances of the two models in reproducing historical records were good at daily and monthly time scale both on calibration and validation (NSE $=0.91$ for $\mathrm{HBV}$ and $\mathrm{NSE}=0.88$ for GR4J). The models results in predicting hydrological response of changed climate (2015-2050) was simulated using statistically downscaled 20 ensembles climate scenario data for both A1B and B1 scenarios. Both model results showed a reduction of the peak discharge in August and September The total annual discharge for future period (2015-2050) showed a decreasing trend for HBV-Light simulation and an increasing trend for GR4J simulation. More studies using different hydrological models on different catchments need to be carried out in order to provide more general conclusions about the reliability of the model output.
\end{abstract}

Keywords: Gr4J, HBV-Light, Megech, REMO, SDSM

DOI: $10.7176 / J N S R / 9-1-03$

\section{Introduction}

Rainfall-runoff models are very important tools for simulating the impact of watershed processes and management on soil and water resources [9]. Rainfall-runoff models have been under a continuous state of development. In order to model rainfall-runoff process, a variety of hydrological models have been applied .The impact of climate change on the hydrology using a single most common hydrological model have been extensively discussed in the scientific literature. However, for a given catchment, the uncertainty obtained when different hydrological models are used for a given climate scenario has not been widely investigated and reported in the literature [16].

No comparative study of hydrological models had been performed for the Megech catchment of the Abbay basin, even though conceptual and physically based models have been applied in the Abbay basin (e.g., Abdo et al. 2009; Zemede 2013; Hailyesus 2011). Therefore it is wise to compare different hydrological models in a given catchment and recommend which one of the model is more appropriate for a given topographic and climatic condition.

The objective of this study was to compare the performance and comparative uncertainty of two different conceptual rainfall-runoff models (i.e., HBV-Light and GR4J models).

\section{Materials and Methods}

\subsection{Study Area}

The Blue Nile (Abbay) River Basin lays in the western part of Ethiopia, between $7^{0} 45^{\prime}$ and $12^{0} 45^{\prime} \mathrm{N}$, and $34^{0} 05^{\prime}$ and $39^{\circ} 45^{\prime} \mathrm{E}$. It accounts for almost $17.1 \%$ of Ethiopia's land area and about $50 \%$ of its total average annual runoff. The Abbay basin is dominated by an altitude ranging from 590 m.a.s.l. to more than 4000 m.a.s.l. Megech catchment is located in the Northwest part of Ethiopia between $12^{0} 29^{\prime} 00^{\prime \prime}$ to $12^{0} 43^{\prime} 40^{\prime \prime}$ latitude and $37^{0} 23^{\prime} 53^{\prime \prime}$ to $37^{0} 33^{\prime} 35^{\prime \prime}$ longitude with an approximation altitude range between 1849 and 2942 m.a.s.l. The catchment covers a total surface of $513 \mathrm{~km}^{2}$ as shown in Figure 1 


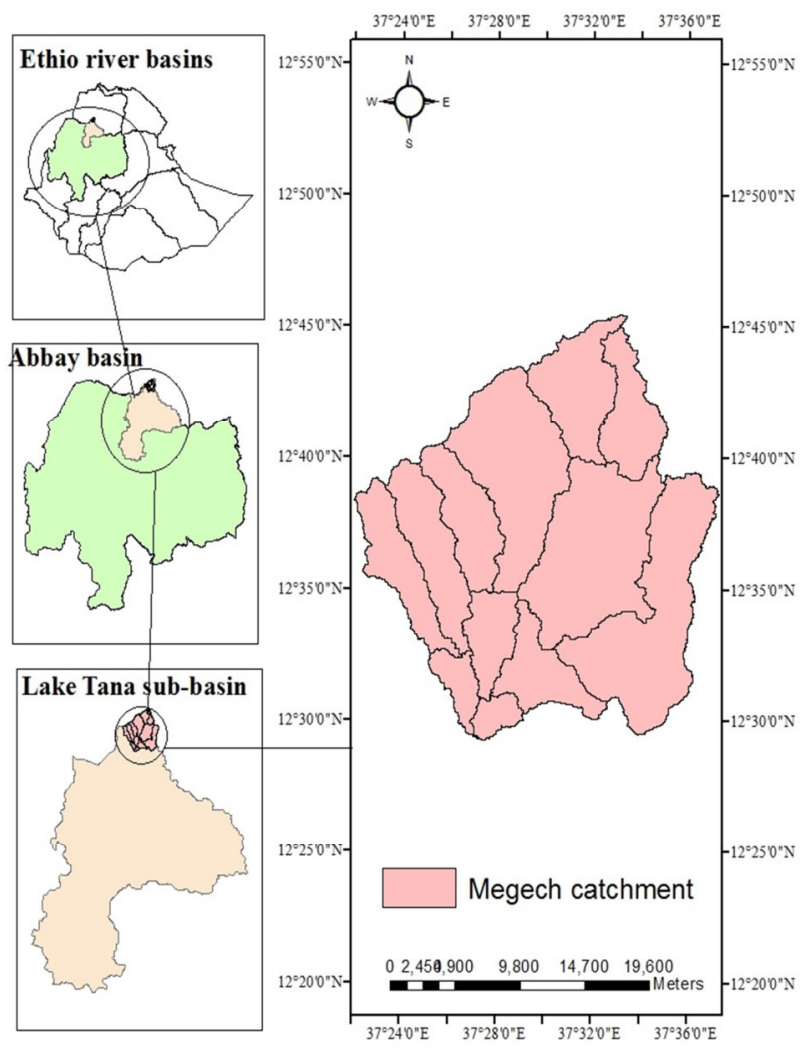

Figure 1 Location of Megech catchment

\subsection{Methodology}

In this work, the output variables from REMO (Regional Climate Model) for both emission scenarios of A1B and B1 were statistically downscaled by using Statistical Downscaling Model (SDSM) version 5.11. Both Hydrological models, GR4J and HBV-Light, were calibrated and validated using historical climate data of three stations (Ambagiorgis, Gondar and Maksengit) and observed discharge data of Megech river. The downscaled future scenario 20 ensembles data of both REMO A1B and B1 scenario were used as an input for both conceptual models to compare the performance and uncertainties of the two models and the catchment hydrological response to climate change.

Data Availability

Metrological data has been required for this study to be used as an input for both hydrological models and for downscaling REMO data using Statistical Downscaling Model (SDSM). Based on these daily metrological data was collected from Ethiopian National Metrological Service Agency (NMSA) for stations that found in and around the catchment. The choice of stations was based on the length of time series data and its extent in catchment network. The metrological variables used for this study were daily rainfall, maximum and minimum temperature. The location of meteorological stations and the extent of data used for this study are shown in Table 1 below.

The stream flow data of Megech River were used as an input for calibrating and validating of both HBVLight and GR4J models. The gauging station of Megech River was located at Gondar Zuria wereda near Azezo $\left(12^{0} 29^{\prime} 0^{\prime \prime} \mathrm{N}\right.$ and $\left.37^{0} 27^{\prime} 0^{\prime} \mathrm{E}\right)$. Daily stream flow data (1980-2000) of this station was collected from Ministry of Water, Irrigation and Energy (MoWIE).

Climate Model and Downscaling

For this study the climate scenario data (A1B and B1) were extracted from REMO model based on longitude and latitude that had grid resolution of $50 \mathrm{~km}\left(0.5^{0}\right.$ latitude by $0.5^{0}$ longitude grid size).The coarser climate data (REMO output) further downscaled in to station level by using statistical downscaling model (SDSM version 5.1.1) and these downscaled data was taken directly as an input to the hydrological models to assess the future climate change impact on hydrology of the catchment. 
Table 1. Metrological stations and data periods used in this study

\begin{tabular}{|l|l|l|l|l|l|l|}
\hline Station & $\begin{array}{l}\text { Elevation } \\
(\text { meter })\end{array}$ & $\begin{array}{l}\text { Lat } \\
(\text { degree })\end{array}$ & $\begin{array}{l}\text { Lon } \\
\text { (degree) }\end{array}$ & $\begin{array}{l}\text { Precipitation } \\
\text { (Years) }\end{array}$ & $\begin{array}{l}\text { Maximum } \\
\text { Temperature } \\
\text { (Years) }\end{array}$ & $\begin{array}{l}\text { Minimum } \\
\text { Temperature } \\
\text { (Years) }\end{array}$ \\
\hline Ambagiorgis & 2900 & 12.76 & 37.6 & $1980-2000$ & $1980-2000$ & $1980-2000$ \\
\hline Gondar & 1912 & 12.56 & 37.43 & $1971-2000$ & $1971-2000$ & $1971-2000$ \\
\hline Maksengit & 1973 & 12.52 & 37.56 & $1971-2000$ & $1978-2000$ & $1978-2000$ \\
\hline
\end{tabular}

SDSM downscaling method had been selected cheap, computationally undemanding and readily transferable compared to other downscaling methods (Wilby and Dawson, 2007).

For this study the REMO grid nodes data were takes as predictors and the station data were taken as predictands. The catchment was covered by 8 REMO raster nodes. Among those 3 grids nodes were used for downscaling. The base line data for the base period were from 3 stations in and around the Megech catchment within the range of 30 to 21 years period from 1971-2000 and 1980-2000 respectively. The first 20 (1971-1990) to 14 (1980-1993) years of data were considered for calibrating SDSM while the remaining 10 (1991-2000) to 7 years (1994-2000) respectively, were used for validation. After calibrating SDSM model, the future climate scenarios (2015-2050) was generated based on the calibrated parameter and large scale predictor (REMO predictor) based on the mean of 20 ensembles for both A1B and B1 scenarios. The downscaled data was taken directly as an input to the hydrological models to compare the performance of both models in simulating future discharge.

\section{Hydrological Modeling}

To simulate the water balance components of the catchment, two conceptual hydrological models namely, GR4J and HBV-Light, were used. The short description of the models is discussed in the following sections. GR4J and HBV-Light models had been selected due to the fact that both models are conceptual, requires less input data, easy to calibrate and validate (Seibert 2005; Perrin et al. 2003) and also their applicability had been tested in different catchments of the country (e.g., Abdo et al. 2009; Hailyesus 2011; Asfaw et al. 2014).

\section{HBV-Light Model}

The HBV (Hydrologiska Byråns Vattenbalansavdelning) Light hydrology model is a widely used conceptual model, that simulates daily discharge using daily rainfall, temperature and potential evapotranspiration as input (Figure 2). (Seibert, 2005). The model has four routines for discharge simulation. (i) The 'snow routine' was ignored in this study due to absence of snow in the study area. (ii) The 'soil routine' is a process where rainfall goes to the root zone and to groundwater as recharge depending on the relation between field capacity (FC (mm)) and moisture content in the root zone (SM (mm)) (Eq. 1), and actual evaporation is estimated depending on soil moisture availability using the relation between SM and FC (Eq. 2). (iii) The 'response routine' is for computing routine' is used to transform runoff to simulated runoff ( $\mathrm{mm} /$ day) (Eqs 4 and 5) using a triangular weighting function defined by the parameter MAXBAS (Seibert, 2005).

$$
\begin{aligned}
& \frac{\text { recharge }}{\mathrm{P}(\mathrm{t})}=\left(\frac{\mathrm{SM}(\mathrm{t})}{\mathrm{FC}}\right)^{\text {BETA }} \\
& \mathrm{E}_{\text {act }}=E_{P o t} \mathrm{~m}\left(\frac{\mathrm{SM}}{\mathrm{FC} . \mathrm{LP}}, 1\right) \\
& Q_{G W}=K_{2} S L Z+K_{1} S U Z+K_{o} \operatorname{Max}(S U Z-U Z L, 0) \\
& \mathrm{Q}_{\operatorname{sim}(\mathrm{t})}=\sum_{\mathrm{i}=1}^{\mathrm{MAXBAS}} \mathrm{C}(\mathrm{i}) Q_{G W}(\mathrm{t}-\mathrm{i}+1) \\
& \mathrm{C}(\mathrm{i})=\int_{\mathrm{i}-1}^{\mathrm{i}} \frac{2}{\mathrm{MAXBAS}}-\left|\mathrm{U}-\frac{\mathrm{MAXBAS}}{2}\right| \frac{4}{\mathrm{MAXBAS}^{2}} \mathrm{du}
\end{aligned}
$$

Where $\mathrm{P}(\mathrm{t})$ is the precipitation at time $\mathrm{t}, \mathrm{FC}$ is the field capacity, BETA is a parameter that determines the relative contribution to runoff from rain or snow melt, Eact is the actual evapotranspiration,Epot is the potential evapotranspiration, LP is the soil moisture value above which ET act reaches ETpot, QGWis the groundwater recharge, Qsim is the simulated runoff and $\mathrm{Ki}$ is the recession constant. A more detailed description of the model can be found in Seibert (2005). The main calibration parameters for HBV-Light model are listed in Table 2. 
Table 2. Main calibration parameters of HBV-Light model

\begin{tabular}{|c|c|c|c|c|}
\hline Routine & Parameters & Description & Range & Optimized value \\
\hline Soil Moisture & FC & Maximum soil moisture storage (mm) & $100-550$ & 127.40 \\
\hline \multirow[t]{2}{*}{ Routine } & LP & $\begin{array}{l}\text { soil moisture value above which } \\
\text { ETact reaches ETpot }(\mathrm{mm})\end{array}$ & $0.3-1.0$ & 1.0 \\
\hline & Beta & $\begin{array}{l}\text { Parameter that determines the relative } \\
\text { contribution to runoff from rain or } \\
\text { snow melt (-) }\end{array}$ & $0.5-6$ & 0.78 \\
\hline \multirow[t]{5}{*}{ Response routine } & PERC & $\begin{array}{l}\text { Max. percolation to lower zone ( } \mathrm{mm} \\
\text { day }^{-1} \text { ) }\end{array}$ & $0-10$ & 8.33 \\
\hline & UZL & threshold parameter $(\mathrm{mm})$ & $0-30$ & 19.99 \\
\hline & K0 & Recession coefficient $\left(\right.$ day $\left.^{-1}\right)$ & $0.1-0.5$ & 0.15 \\
\hline & $\mathrm{K} 1$ & Recession coefficient $\left(\right.$ day $\left.^{-1}\right)$ & $0.01-0.5$ & 0.01 \\
\hline & $\mathrm{K} 2$ & Recession coefficient $\left(\right.$ day $\left.^{-1}\right)$ & $0.001-0.1$ & 0.09 \\
\hline Routing Routine & MAXBAS & Triangular weighing function & $1-10$ & 9.9 \\
\hline
\end{tabular}

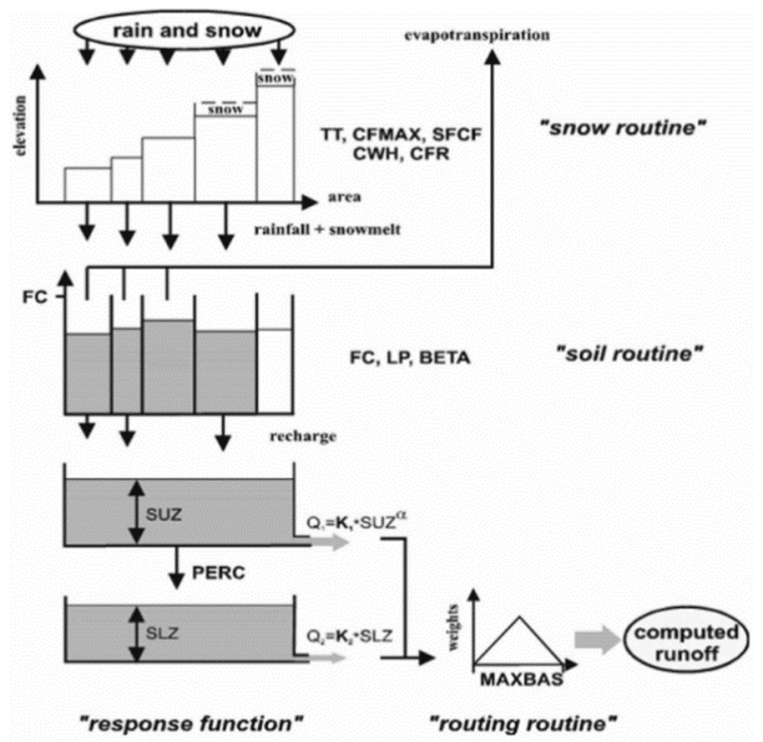

Figure 2 General structure of the HBV model (Seibert, 2005).

\section{Model input}

The conceptual HBV-Light model computes runoff from observed daily rainfall, daily temperature, long-term monthly potential evapotranspiration and runoff data. The daily areal rainfall (1991-2000) was calculated by Thiessen polygon method. Potential evapotranspiration for the study area was estimated by the Hargreaves method. The Hargreaves method had been selected because it requires less metrological data (maximum and minimum temperature) compared to other methods (Hargreaves et al, 1982).

\section{Model calibration and validation}

Parameter sensitivity analysis was conducted using the GAP optimizations to find the range, then after manual calibration was conducted to get the best fit parameters according to the objective functions. The total period of the data that was used for this specific study was 8 years. From this period by using split sample technique $2 / 3^{\text {rd }}$ of the data (1991-1995) were used for calibration and the remaining $1 / 3^{\text {rd }}$ of the data $(1998-2000)$ of the catchment were applied for validation.

\section{GR4J Model}

The GR4J daily model is one of the simple daily lumped conceptual rainfall-runoff models (Perrin et al., 2003).It is a lumped model considering the basin as a whole and averaging every data on its surface. GR4J model is rainfall runoff modeling which was based on four free parameters from daily rainfall data.

The model estimates stream flow from daily areal rainfall and potential evapotranspiration (PET). It belongs to the family of soil moisture accounting models. It is made up of a production store and a routing store. The general model structure is shown in Figure 3. 


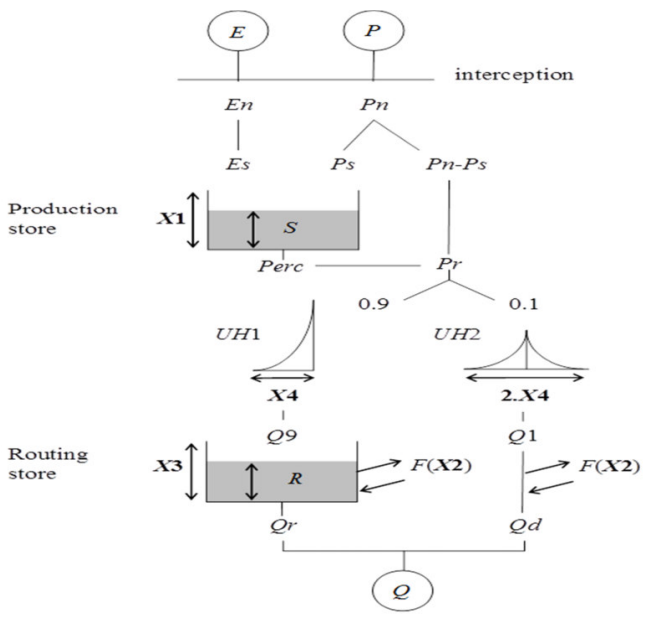

Figure 3. GR4J model structure (Perrin et al., 2003)

\section{Model input}

The input data required by the model are areal average daily precipitations and evapotranspiration of the catchment, as well as daily discharge values at the outlet of the catchment. Similar procedure as incase of HBVLight was followed for determining areal rainfall and evapotranspiration of the catchment.

\section{Model calibration and validation}

The model had four parameters that are summarized in Table 2 (Perrin et al., 2001). During the calibration process those four parameters were optimized in order to find the combination that reaches the best fit between the simulated and the observed discharge. In the validation process, the same criteria were used to assess the quality of the calibration of four parameters on a new data set. For the sake of comparing the uncertainty of the two selected conceptual hydrological models the same input and year length of the data were used for both calibration and validation as HBV-Light model as it described above (i.e. $2 / 3^{\text {rd }}$ of the data (1991-1995) have been used for calibration, and the remaining $1 / 3^{\text {rd }}$ of the data $(1998-2000)$ of the catchment was applied for validation.).

Table 3. GR4J model parameters (Perrin et al., 2001).

\begin{tabular}{ll}
\hline Parameter & Description \\
\hline $\mathrm{X}_{1}$ & Production store capacity $(\mathrm{mm})$ \\
$\mathrm{X}_{2}$ & Exchange coefficient $(\mathrm{mm})$ \\
$\mathrm{X}_{3}$ & Routing Store capacity $(\mathrm{mm})$ \\
$\mathrm{X}_{4}$ & Base time of UH1(day)
\end{tabular}

\section{Model Performance Criteria}

For this particular study, three performance criteria namely NSE, R ${ }^{2}$ and RVE were used. Nash and Sutcliffe efficiency (NSE) was proposed by Nash and Sutcliffe (1970), its value lies between 1.0 (perfect fit) and $-\infty$. Coefficient of determination $\left(\mathrm{R}^{2}\right)$ is expressed as (Krause et al., 2005) the squared ratio between the covariance and the multiplied standard deviations of the observed and predicted. Relative volume error (RVE) can vary between $\infty$ and - $\infty$ but it performs best when a value of 0 (zero) is generated.

\section{Results and Discussion}

\subsection{Comparison of Models Results in Reproducing Historical Records}

The hydrographs resulted using the above optimized parameters are presented in figure 4 and 5 . The performance of the model has been evaluated using both graphical and statistical criteria. On graphical analysis the agreement between observed and simulated discharge was evaluated through visual inspection. Another evaluation criterion for comparing the selected models is to use statistical criterion which evaluates a distance between the measured and simulated flow values over a chosen time period. The statistical criteria's selected for comparing the models are Nash-Sutcliffe efficiency (NSE), coefficient of determination $\left(\mathrm{R}^{2}\right)$ and Relative Volume Error (RVE) have been used. According to those criteria's selected for comparison both models showed good performance for daily and monthly calibration (with NSE $=0.91$ and $\mathrm{R}^{2}=0.92$ for HBV-Light and $\mathrm{NSE}=0.88$ and $\mathrm{R}^{2}=0.89$ for GR4J for monthly simulation). In addition, the models were validated using independent data set, which shows good agreement for both daily and monthly simulation results (with NSE= 0.86 and $\mathrm{R}^{2}=0.87$ for HBV-Light and $\mathrm{NSE}=0.83$ and $\mathrm{R}^{2}=0.84$ for GR4J for monthly simulation). The 
performance of both models was better in monthly time steps. Generally speaking, the results show that both models can reproduce historical daily discharge with an acceptable accuracy. However there is a performance difference between them based on the selected criteria's. On both daily and monthly calibration and validation HBV-Light performs better than GR4J model and HBV-Light model was also better than GR4J model in simulating low flows and medium flows and GR4J was good at simulating peak flows. The calibration and validation result of both models is shown in figures below.

Generally, according to the performance evaluation criteria set for comparison the GR4Jis poor in capturing low and medium flows and it is better in capturing peak flow on better way than HBV-Light. Hydrological studies done using GR4J models also shows similar result that the model is poor in capturing low flows (Zhang et.al., 2013; Safouane et.al., 2013; Yohann, 2011). The correlation plots of both models against the measured discharge which is presented in Figure 30 showed that there is a good agreement between observed and simulated discharge even though HBV-Light $\left(\mathrm{R}^{2}=0.91\right)$ performs a little bit better than GR4J model $\left(\mathrm{R}^{2}=0.89\right)$.

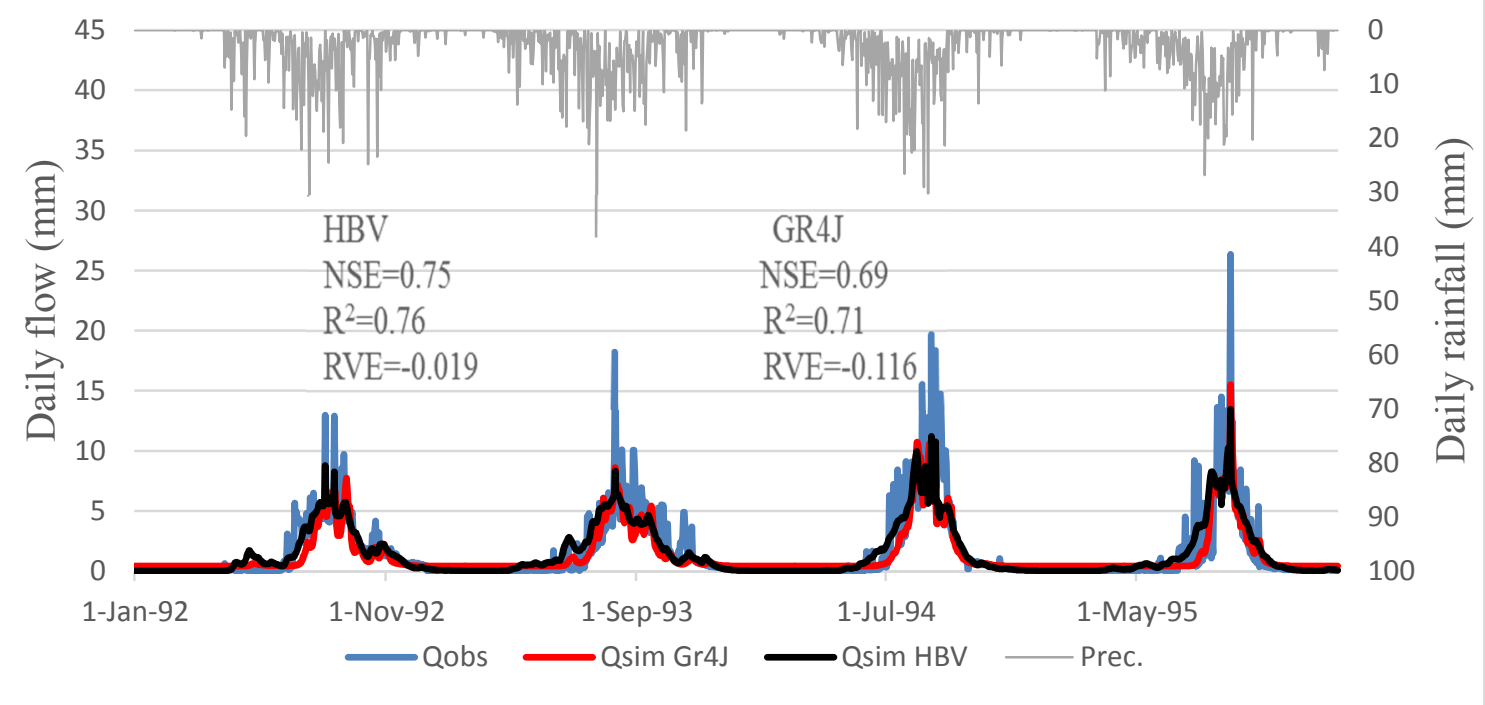

(a)

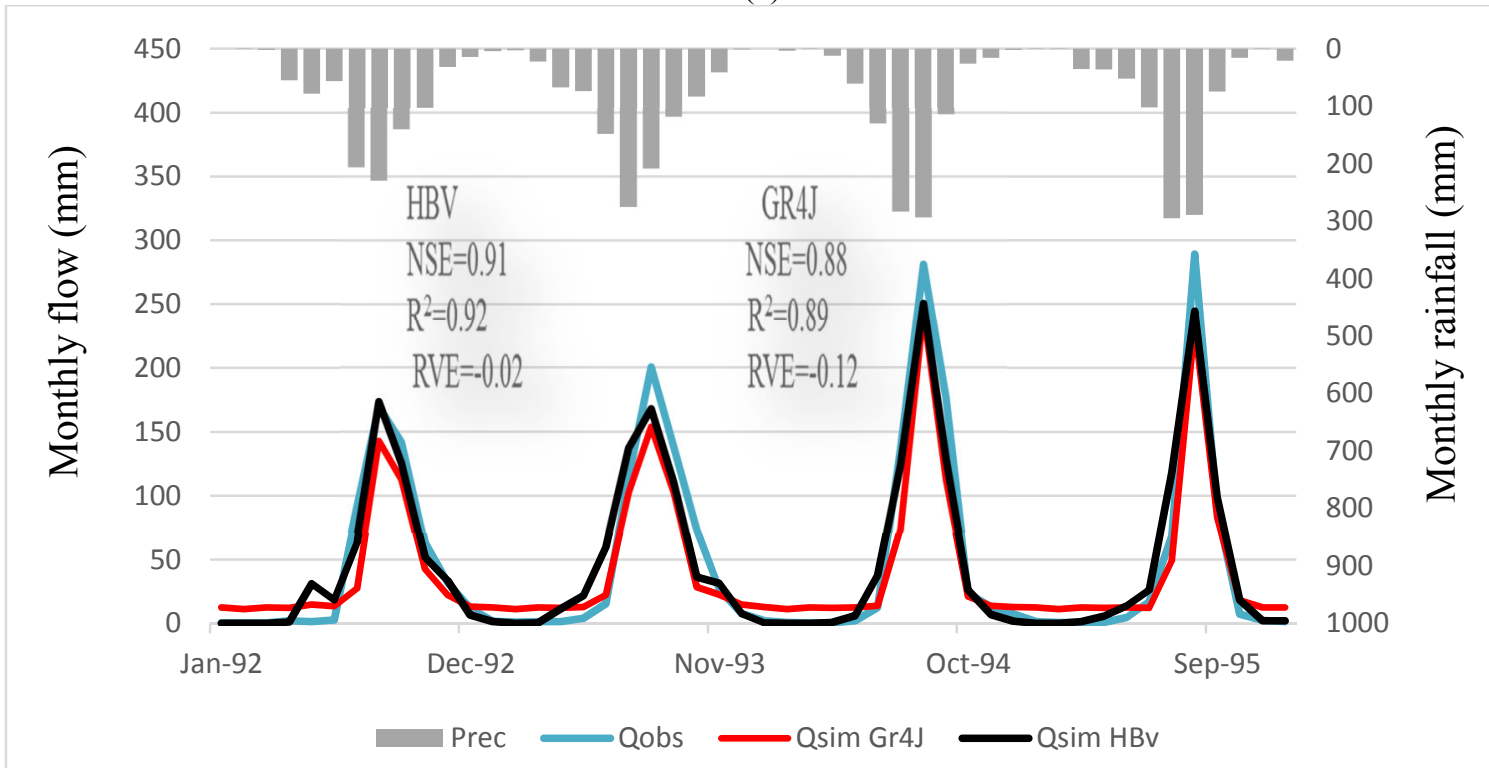

(b)

Figure 4: Daily (a) and monthly (b) calibration result of Megech catchment (1992-1995) 


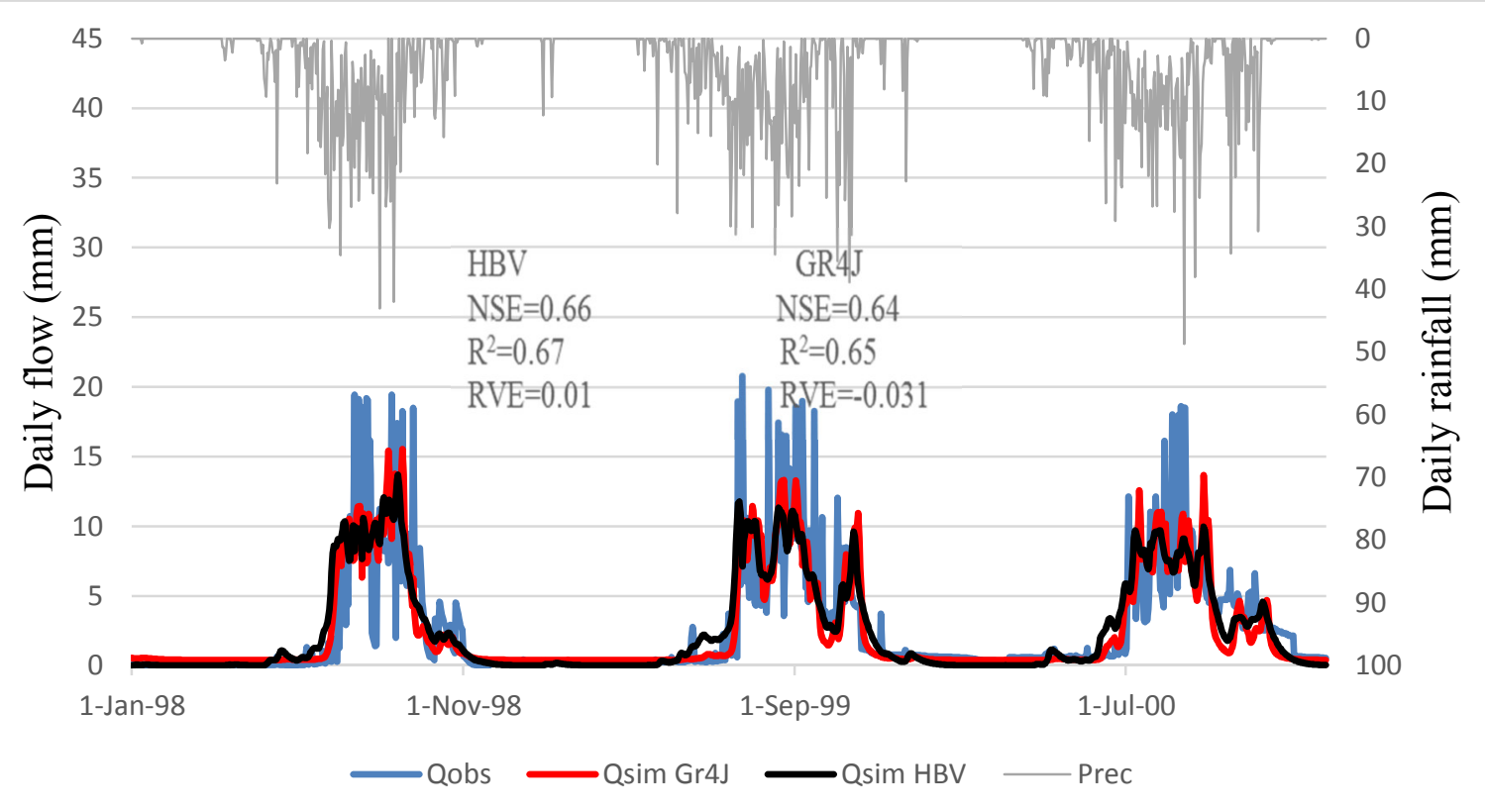

(a)

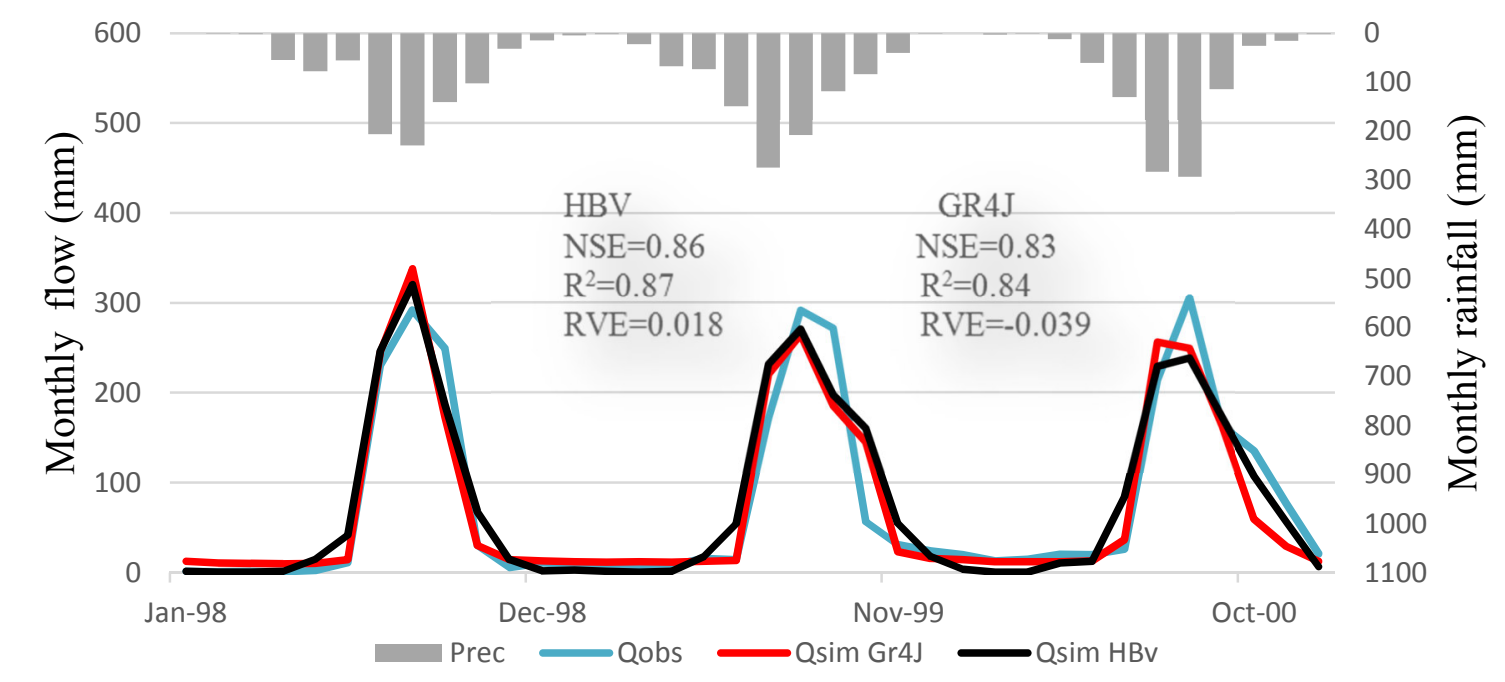

(b)

Figure 5: Daily (a) and monthly (b) Validation of Megech catchment (1998-2000) 


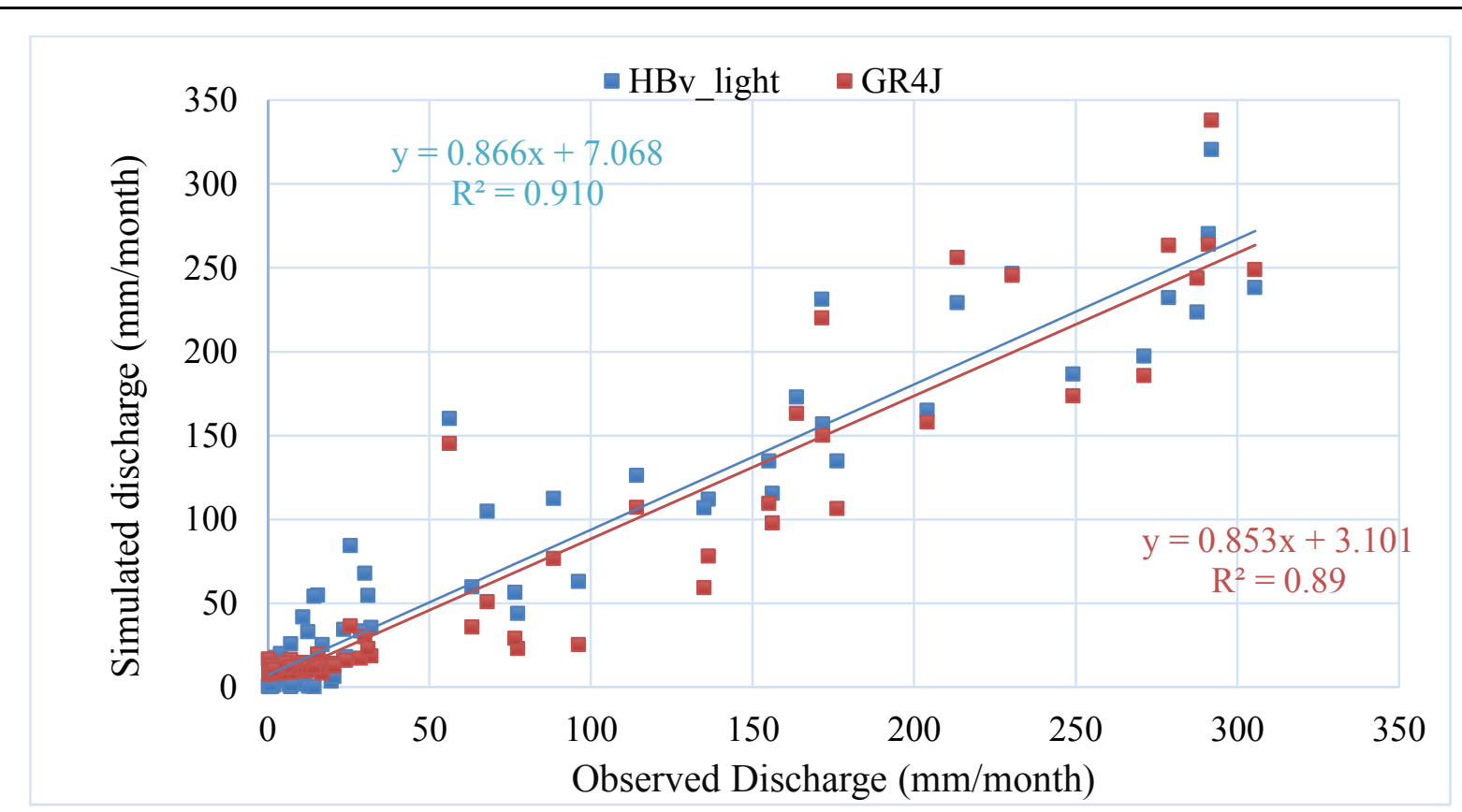

Figure 6: Correlation plots of GR4J and HBV-Light for the whole period

\subsection{Differences of Models Results in Predicting Hydrological Response of Changed Climate}

For comparing the two hydrological models under climate change scenarios, 20 ensembles of climate variables (i.e. Precipitation and temperature) for both REMO A1B and B1 scenario were generated). Each 20 ensembles of climate data have been used as an input and the maximum and minimum ensembles were selected to find the range of discharge change for future period (2015-2050). As displayed on figure 5 and 6 , both hydrological models showed that, there would be a reduction of peak flow for August and September however the change was observed higher for HBV-Light model $(-17.47 \% \%$ to $-30.58 \%)$ than GR4J model $(-11.6 \%$ to $-17.8 \%)$. This is may be mainly because of during those periods temperature showed no change while Precipitation expected to be fall down up to $-10 \%$.

For low flow of the dry season (November to April), there would be an increment of both maximum temperature $\left(+0.57^{\circ} \mathrm{C}\right)$ and precipitation $(+38.39 \%)$, HBV-Light simulation result showed almost no change except for the month of April which showed an increasing trend, while all GR4J simulation result revealed that there would be an increasing trend for both scenarios.

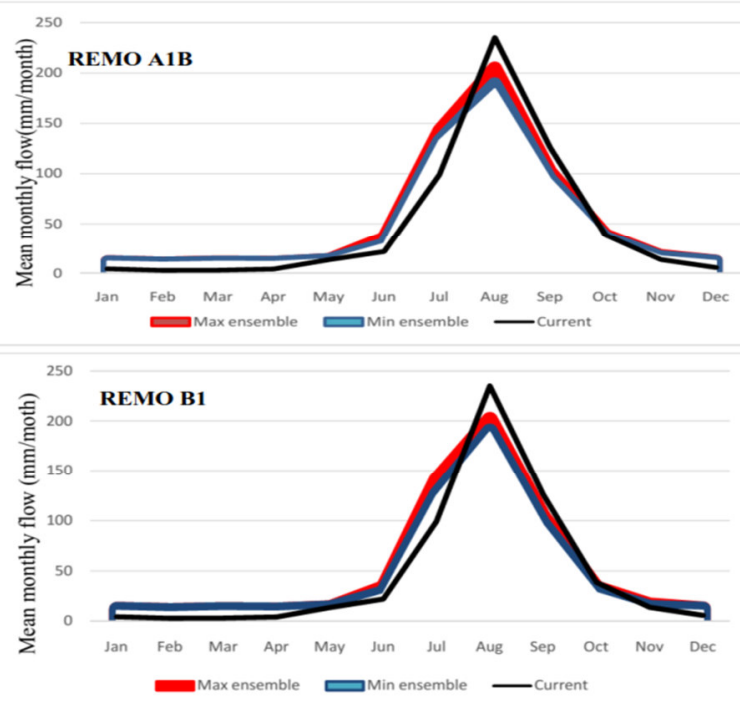

Figure 7 Comparison of current and future period discharge (2015-2050) for maximum and minimum ensembles of REMO A1B and B1 Sc0enarios as it simulated by GR4J model 


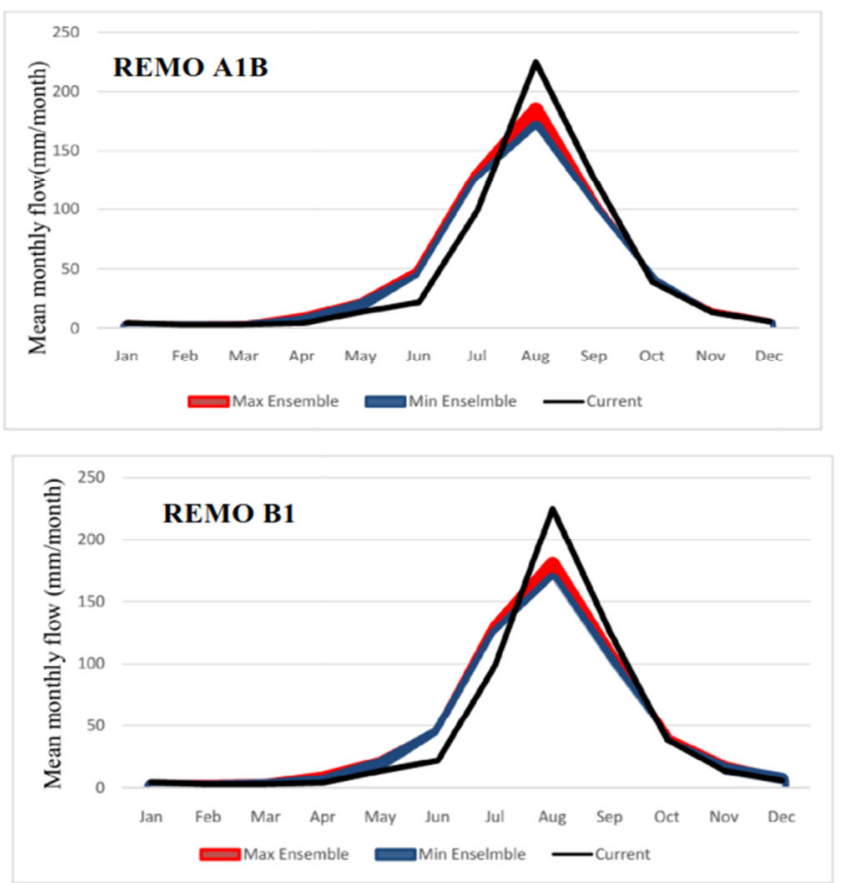

Figure 8 Comparison of current and future period discharge (2015-2050) for maximum and minimum ensembles of REMO A1B and B1 Scenarios as it simulated by HBV-Light model

Generally the mean annual simulated water balance for the observed period and future climate change scenarios is portrayed in Table 4. The table results are the averages of the 20 ensemble run for each climate scenario of potential evapotraspiration (ETP), actual evapotraspiration (ETR) and total discharge (QT). Change in $\%$ from the reference period is portrayed below.

Table 4: Mean simulated annual water balance for the observed period and future climate change REMO A1B and B1 scenarios in the Megech river catchment.

\begin{tabular}{|c|c|c|c|c|c|c|c|}
\hline & & $\begin{array}{l}\mathrm{Q}_{\mathrm{T}} \\
(\mathrm{mm})\end{array}$ & $\begin{array}{l}\text { ETP } \\
(\mathrm{mm})\end{array}$ & $\begin{array}{l}\text { ETR } \\
(\mathrm{mm})\end{array}$ & $\begin{array}{l}\mathrm{Q}_{\mathrm{T}} \\
(\Delta \%)\end{array}$ & $\begin{array}{l}\text { ETP } \\
(\Delta \%)\end{array}$ & $\begin{array}{l}\text { ETR } \\
(\Delta \%)\end{array}$ \\
\hline & $\begin{array}{l}\text { Observed }(1991-1995,1998- \\
2000)\end{array}$ & 559 & 1424 & 433 & 0 & 0 & 0 \\
\hline & REMO A1B & & & & & & \\
\hline & 2015-2024 & 545.76 & 1459.13 & 485.62 & -2.37 & +2.46 & +12.15 \\
\hline & $2025-2034$ & 543.78 & 1460.0 & 477.58 & -2.72 & +2.52 & +10.29 \\
\hline & $2035-2044$ & 531.08 & 1463.76 & 475.53 & -4.99 & +2.79 & +9.82 \\
\hline HBV- & $2045-2050$ & 534.60 & 1462.49 & 477.08 & -4.36 & +2.70 & +10.18 \\
\hline \multirow[t]{12}{*}{ Light } & REMO B1 & & & & & & \\
\hline & $2015-2024$ & 539.62 & 1435.6 & 487.16 & -3.46 & +0.81 & +12.50 \\
\hline & $2025-2034$ & 540.0 & 1439.8 & 478.20 & -3.39 & +1.10 & +10.43 \\
\hline & 2035-2044 & 531.80 & 1438.71 & 478.11 & -4.86 & +1.03 & +10.41 \\
\hline & REMO A1B & & & & & & \\
\hline & 2015-2024 & 605.24 & 1459.13 & 382.71 & +8.27 & +2.46 & -11.61 \\
\hline & $2025-2034$ & 604.23 & 1460.0 & 376.52 & +8.09 & +2.52 & -13.04 \\
\hline & 2035-2044 & 598.69 & 1463.76 & 380.52 & +7.10 & +2.79 & -12.12 \\
\hline & $2045-2050$ & 599.36 & 1462.49 & 395.80 & +7.22 & +2.70 & -8.59 \\
\hline & REMO B1 & & & & & & \\
\hline & $2015-2024$ & 602.50 & 1435.6 & 385.96 & +7.78 & +0.81 & -10.86 \\
\hline & $2025-2034$ & 609.50 & 1439.8 & 379.39 & +9.03 & +1.10 & -12.38 \\
\hline \multirow[t]{2}{*}{ GR4J } & $2035-2044$ & 600.30 & 1438.71 & 384.42 & +7.38 & +1.03 & -11.21 \\
\hline & $2045-2050$ & 589.78 & 1446.25 & 398.90 & +5.50 & +1.56 & +7.87 \\
\hline
\end{tabular}

\section{Conclusions and Recommendations}

\subsection{Conclusions}

The calibration and validation results of HBV-Light and GR4J models were driven by observed hydro climatic data The overall model result shows that the models are able to reproduce discharge with good performance 
(HBV-Light; $\mathrm{R}^{2}=0.92, \mathrm{NSE}=0.91 \quad \mathrm{RVE}=-0.02$ and $\mathrm{GR} 4 \mathrm{~J} ; \mathrm{R}^{2}=0.89, \mathrm{NSE}=0.88$ and $\mathrm{RVE}=-0.12$ ). The performances of the two models in simulating future discharge were tested using downscaled REMO climate scenario data. Both hydrological models showed a decrease in peak discharge (August and September) for all downscaled REMO scenarios.

According to the results, the sources of uncertainty in hydrological impact study are not only linked to using different climate models, but also with the differences resulting from using different hydrological simulation models.

\subsection{Recommendations}

The study focused in comparison of two conceptual hydrological models mainly based on climatic variables, for instance temperature, precipitation and evapotranspiration. The study should be extended by considering other related parameter like land use-land cover and including physically distributed models like SWAT \& WaSiMETH.

Future water resources scenarios predicted by both hydrological models showed a different trend. More studies using different hydrological models on different catchments need to be carried out in order to provide more general conclusions about the reliability of the model output.

\section{References}

Abdo KS, Fiseha BM, Rientjes TH, Gieske AS. and Haile AT 2009. Assessment of climate change impacts on the hydrology of Gilgel Abay catchment in Lake Tana basin, Ethiopia .Hydrol. Process. 23, 3661-3669.

Asfaw K, 2013. Downscaling climate model outputs for estimating the impact of climate change on water availability over the Baro-Akobo river basin, Ethiopia. Doctoral dissertation., Bonn University, Germany.

Beyene T, Lettenmaier DP, Kabat P 2010.Hydrological impact of climate change on the Nile river basin; implication of the 2007 IPCC scenarios. Climate change 100:433-461

Getachew T, Dereje H, and Moses, A 2013. Lake Tana reservoir water balance model. International Journal of Application or Innovation in Engineering and Management. 2( 3), 474-478.

Haileyesus B 2011. Evaluation of climate change impacts on hydrology on selected catchments of Abbay basin. M.Sc Thesis, institute of technology, Addis Ababa University, Addis Ababa, Ethiopia.

IPCC (Intergovernmental Panel on Climate Change). 2007: Climate change 2007: the physical science basis. Contribution of working group II to the fourth assessment report of the Intergovernmental Panel on Climate Change. Cambridge University Press, Cambridge, UK.

Jacob D 2001. A note to the simulation of the annual and inter-annual variability of the water budget over the Baltic Sea drainage basin. Meteorology and Atmospheric Physics, 77 (1-4).

Krause P, Boyle DP, and Bäse F 2005. Comparison of different efficiency criteria for hydrological model assessment. Advances in Geosciences, 5, 89-97.

Moriasi, D., Arnold, G., Van Liew,W., Bingner, L.,. Harmel, D., Veith, L. 2007. Model evaluation guidelines for systematic quantification of accuracy in watershed simulations. Trans. ASABE, 50, 885-900.

Nash JE, and Sutcliffe JV 1970. River flow forecasting through conceptual models, Part I-a discussion of principles. Journal of Hydrology, 10 (3), 282-290.

Perrin C, Michel C, and Andréassian V 2003. Improvement of a parsimonious model for stream flow simulation. Journal of Hydrology 279 (1-4), 275-289.

Safouane. M, Khaoula. M, and Fethi .L. 2013. A Structural overview through GR(s) models characteristics for better yearly runoff simulation. Open Journal of Modern Hydrology, 2013, 3, 179-187.

Seibert, J. 2005) HBV Light Version 2. User's manual. Department of Physical Geography and Quaternary Geology, Stockholm University.

Shimelis S, Ragahavan S, and Bijan D, 2008. Hydrological modelling in the Lake Tana basin, Ethiopia using SWAT model. The Open Hydrology Journal, 2008, 2, 49-62.

Speth P, Christoph M, and Diekkruger,B 2010. Impacts of global change on the hydrological cycle in West and Northwest Africa. Heidelberg: Springer, 675.

Tao J., Yongqin .D., Chong-yu X ., Xiaohong .C. , Xi .C, and Vijay P. 2007. Comparison of hydrological impacts of climate change simulated by six hydrological models in the Dong jiang Basin, South China. Journal of Hydrology 336, 316- 333.

Tewodros T 2012. Physically based rainfall runoff Modeling in the Northern Ethiopian highlands: the case of Mizewa watershed. M.Sc. Thesis, Bahirdar University, Bahirdar, Ethiopia.

Wilby LR, Zorita E, Timbal B,Whetton P, Mearns LO, and Charles SP 2004. Guidelines for use of climate scenario developed from statistical downscaling methods. Environmental Agency of England and wales, UK.

Yohann Tondu, 2011. Simulation of the Paris 1910 flood with a lumped hydrological model: the influence of frozen soil. M.Sc Thesis, department of land and water resources engineering, Royal Institute of 
Technology (KTH), Sweden.

Zemede M. 2013. Hydrological impacts of climate change on Lake Tana's water balance. M.Sc. Thesis, Faculty of Geo-Information Science and Earth Observation, University of Twenty, The Netherlands.

Zhang, X, Waters, D. and Ellis, R.., 2013. Evaluation of Simhyd, Sacramento and GR4J rainfall runoff models in two contrasting Great Barrier Reef catchments. 20th International Congress on Modeling and Simulation, 1-6 December 2013, Adelaide, Australia. 